\title{
A CONSTRUÇÃO DA IDENTIDADE PROFISSIONAL DO PROFESSOR DE LÍNGUA INGLESA POR MEIO DO DISCURSO EM CONTEXTO ONUINE
}

Valkíria Bento Luiz ${ }^{* *}$

Resumo: O objetivo deste trabalho é analisar o discurso do professor-aluno de língua inglesa a fim de compreender e descrever como ele se reconhece como profissional. O estudo se insere sob a perspectiva teórico-metodológica da Linguística Sistêmico-Funcional (HALLIDAY, 1994; HALLIDAY \& MATTHIESSEN, 2004) que busca estudar a função social da língua em uso. A análise buscou apreender as representações do professor-aluno que se materializam em suas escolhas linguísticas. Os participantes são professores-alunos de um curso de formação para professores de Língua inglesa, Teachers' Links, em contexto online. As conclusões apontam que o processo mental é o mais recorrente e está presente em orações relacionadas à experiência de mundo da consciência dos participantes, os significados de pensar e sentir.

Palavras-chave: Formação de professor. Professor de língua inglesa. Linguística Sistêmico-Funcional.

Introdução

As novas tecnologias da comunicação e informação e o advento da globalização trouxeram o empoderamento das organizações que acelerou a produção de conhecimento. Isto provocou transformações nas operações produtivas, alterando a estrutura social e trazendo maior qualidade de vida a alguns setores da população. Segundo (VALENTE, 2005, p. 51), para o treinamento docente, dentro da abordagem de uso de mídias, o computador pode ser utilizado com o objetivo de informatizar os processos de ensino que já existem, é uma forma de manter a prática pedagógica vigente. A globalização ressaltou a necessidade formação continuada de professores de língua inglesa que entendesse o contexto de produção de conhecimento quanto ao ensino-aprendizagem de línguas (RICHARDS; RENANDYA, 2002, p. 55) que envolvesse uma reflexão crítica sobre prática docente e a concepção de que a língua estrangeira é um conjunto de habilidades a serviço de expressões sociais - um conjunto rico de instrumentos de comunicação, expressão e construção de conhecimentos (CELANI, 2003).

\footnotetext{
** Mestre em Linguística Aplicada e Estudos da Linguagem, Centro Universitário ENIAC, valkiria.bento@eniac.edu.br
} 
Inserido neste contexto, o professor é um sujeito social, dotado de diferentes experiências conhecimentos, crenças, valores, raízes culturais que influenciam sua prática docente (NÓVOA, 1992); está carregado de fragmentos identitários "todos coexistindo, ao mesmo tempo, na mesma pessoa" (MOITA LOPES 2002: 16). (RICHARDS; RENANDYA, 2002, p. 11) "a noção da mudança das crenças de professores é multidimensional [...], bem como pelos contextos profissionais em que os professores trabalham". Um dos aspectos da identidade é que ela não é fixa, singular, isto é, a identidade varia de acordo com o momento discursivo em que os indivíduos se engajam; do local, de suas interações dentro de um contexto. Vygotsky (1991) o indivíduo é o resultado de um processo sócio histórico, enfatizando o papel da linguagem e da aprendizagem nesse desenvolvimento.

É por meio da linguagem que os indivíduos expressam sua percepção de mundo e posicionamento social. O discurso é o meio através do qual as visões de mundo, crenças e valores são explicitados (FAIRCLOUGH,2001). Em qualquer interação, as pessoas negociam significados objetivando a construção do conhecimento comum a partir da troca de experiências individuais. As escolhas linguísticas (lexicogramaticais) que realizam essas ações expressam o conhecimento sistêmico necessário às diferentes ações da reflexão. A discussão do conhecimento sistêmico enfoca os aspectos gramaticais e lexicais todos para a constituição de cada ação reflexiva. O professor é um sujeito social constituído na e pela linguagem, porque tenta "criar inteligibilidade sobre problemas sociais em que a linguagem tem papel central" (MOITA LOPES, 2006, p. 14); nos mais variados contextos sob a forma dos mais diversos gêneros discursivos.

A reflexão na ação e sobre a ação (SCHÖN, 1992) permeia todo esse processo formativo e fornece as bases para que o próprio formando possa compreender as mudanças nas suas concepções relacionadas ao aprender, planejar, ensinar e se comunicar em ambiente on-line. Porém, a reflexão não acontece ao acaso, ocorre quando são criadas condições com a intenção de provocar a introspecção, o olhar para as próprias representações, sentidos e valores que o professor atribui à sua experiência e à experiência do outro, em busca de compreender criticamente essa ação e propor transformações para a realização de novas ações mais apropriadas ao contexto de aprendizagem.

\section{Pressupostos teóricos}


A linguística sistêmico-funcional (doravante LSF), desenvolvida por Halliday e colaboradores, caracteriza-se por ser uma teoria de língua enquanto escolha motivada pelo uso linguístico; propõe-se a compreender e descrever a linguagem em contexto de uso como um sistema de comunicação humana.

A LSF corresponde a uma teoria geral do funcionamento da linguagem humana, concebida a partir de uma abordagem descritiva baseada no uso linguístico. Além da descrição gramatical, "ela fornece também instrumentos de descrição, uma técnica e uma metalinguagem que são úteis para a análise de textos, pelo que, adicionalmente, pode ser encarada como um modelo de análise textual". (GOUVEIA, 2009, p. 14)

Sob esta perspectiva, qualquer realização linguística está sempre condicionada a três tipos de metafunções: ideacional (representar o meio), interpessoal (estabelecer relações com os outros) e textual (organizar a informação). Vale ressaltar que as três metafunções perpassam todas as instâncias de realização da linguagem.

A metafunção ideacional corresponde representação da experiência do mundo físico e do mundo interior, um modo como falante e ouvinte refletem a "realidade" através da língua, classificando as pessoas, os fatos e acontecimentos ao seu redor. Também através desta função ocorre a expressão de elementos do mundo interno como reações, cognições, percepções e os atos linguísticos de falar e entender. É representada pelo sistema de transitividade. Já a metafunção interpessoal compreende o papel de representar as interações e construções de significados interpessoais com seus interlocutores mediante o sistema de modo. A metafunção textual está relacionada ao fluxo de informação e organiza a textualização através do sistema temático, que permite organizar os nossos significados ideacionais e interpessoais, isto é, as nossas mensagens, num todo linear e coerente.

Neste estudo recorreremos a metafunção ideacional, pois possibilita que a linguagem seja usada para falar sobre o mundo e experiências. A oração é o meio pelo qual isso se dá, uma vez que ela pode expressar os processos que controlam e denotam a realidade. Ela representa um modo de reflexão por meio do sistema de Transitividade que constrói a experiência humana em vários tipos de processos, cada qual representando um tipo de experiência, a qual corresponde um esquema particular de estruturação (HALLIDAY \& MATHIESSEN, 2004). Os processos categorizados são principais: Material, Mental e Relacional; secundários: Verbais, Comportamentais e Existenciais. 


\section{Metodologia}

Esta pesquisa é qualitativa porque estuda a realidade, os sentidos e as interpretações das pessoas envolvidas no discurso do professor de inglês dentro do contexto situacional (ambiente online) e quantitativo na coleta e análise estatística do Corpus.

O contexto da pesquisa é o curso de formação continuada TEACHERS' LINKS, oferecido pela PUCSP em parceria com a Associação Cultura Inglesa de São Paulo, na modalidade EAD; oferece aos participantes condições para uma clara conscientização do professor sobre suas possibilidades de desenvolvimento profissional, acadêmico e pessoal, com aperfeiçoamento de seu desempenho em língua inglesa, de sua capacidade de reflexão crítica sobre o seu papel no ensino e de sua capacidade de planejar e organizar sua ação docente.

O Corpus de análise é composto pelas interações em três fóruns do módulo $O$ Desenvolvimento Profissional e a Sala de Aula: reflexão sobre novos caminhos do curso de formação continuada de professores de Língua Inglesa Teachers' Links, em ambiente online, oferecido em parceria pela Cultura Inglesa e PUCSP, ministrado no período de março a julho de 2013. Os participantes são professores efetivos de língua inglesa de escolas públicas de São Paulo, aqui chamados de professores-alunos.

O contexto de situação são os fóruns: Why look for professional development?(WLPD), Interaction, collaboration, and professional development (ICPD) e How do we listen? (HDWL). Nestes fóruns o participante é levado a refletir sobre sua trajetória e analisar as diferentes possibilidades na sua vida profissional.

Após a escolha, os textos foram transformados em arquivos txt, nomeados de acordo com a abreviatura de seus nomes, assim também foi feito como os seus participantes. Na sequencia, passaram pelo programa computacional WordSmith (WS) Tools 6; que por meio de sua ferramenta WordList, foi possível a criação de listas de palavras que englobam todo o Corpus e selecionar os processos mais frequentes e pelo Concord, ferramenta que possibilita analisar os processos, linha a linha e verificar as palavras que os acompanham.

\section{Análise de dados}


Os primeiros dados obtidos com o uso da ferramenta WS 6 foram as informações estatísticas do Corpus, conforme tabela 1.

Tabela 1: Informações estatísticas do Corpus

\begin{tabular}{|lrrrr|}
\hline Dados estatísticos & \multicolumn{1}{l}{$\begin{array}{l}\text { Fórum: } \\
\text { ICPD }\end{array}$} & $\begin{array}{l}\text { Fórum: } \\
\text { HDWL }\end{array}$ & WLPD & Corpus \\
\hline Tamanho do corpus & 28,203 & 42,849 & 47,629 & 118,681 \\
\hline Total de palavras (tokens) & 4,661 & 7,481 & 4,646 & 20,300 \\
\hline Total de palavras diferentes (types) & 869 & 1,265 & 1,237 & 2,168 \\
\hline
\end{tabular}

A partir da WorldList, foram computados os processos a fim de obter a ideia global das representações no discurso do professor-aluno, conforme apresentado na tabela 2.

Tabela 2 - Ocorrência dos Processos no Corpus

\begin{tabular}{|c|c|c|}
\hline \multirow{4}{*}{ 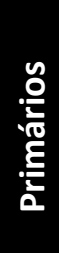 } & PROCESSOS & OCORRÊNCIAS \\
\hline & Mentais & 565 \\
\hline & Relacionais & 471 \\
\hline & Materiais & 360 \\
\hline \multirow{3}{*}{ 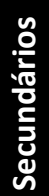 } & Verbais & 185 \\
\hline & Comportamentais & 131 \\
\hline & Existenciais & 102 \\
\hline
\end{tabular}

Os processos mentais, para Halliday (1994), são processos do sentir, do pensar e do perceber. Dentro da categoria geral de processos mentais, estes três constituem os principais subtipos de termos gerais, como: Percepção (ver, ouvir etc); Afeição (gostar, temer etc); Cognição (pensar, saber, compreender etc). Para os participantes, usam-se os termos 
Experienciador e Fenômeno. O Experienciador é o ser consciente que está sentindo, pensando ou vendo. O Fenômeno é aquilo que é sentido, pensado ou visto.

Já os processos relacionais, propostos por Halliday (Ibidem), são aqueles do ser. 0 significado central das orações deste tipo é aquele de que alguma coisa é. Toda língua acomoda, na sua gramática, um número de modos distintos de ser, expressos com tipos diferentes de processos relacionais na oração: intensivo; circunstancial; possessivo. Cada um destes vem em dois modos distintos: atributivo e identificativo.

Os processos materiais, para Halliday (1994), são processos do fazer. Eles expressam a noção de que alguma entidade faz alguma coisa a uma outra. Há um participante obrigatório que faz a ação - o Ator em direção a um outro participante opcional - a Meta.

Quanto aos processos verbais, Halliday (op. Cit.) observa que são processos do dizer. Mas, tem que ser interpretado em um sentido mais amplo; ele cobre um tipo de troca simbólica de significado. A função gramatical de você, eu, o aviso, meu relógio é aquela do Dizente. Duas outras funções participantes operam, segundo ele, regularmente em um processo verbal. Uma é o Receptor, o participante para quem a verbalização é endereçada. 0 outro é um nome para a própria verbalização.

Em relação aos processos comportamentais são (HALLIDAY, 1994), processos do comportamento psicológico e fisiológico, como respirar, sonhar, sorrir, tossir. Gramaticalmente, eles são intermediários entre processos materiais e mentais. 0 Comportante, diz ele, é tipicamente um ser consciente, como o Experienciador; mas a maioria das orações de processos comportamentais tem somente um participante.

O processo existencial representa, no dizer de Halliday (1994), que algo existe ou acontece. Estas orações tipicamente têm o verbo ser, ou algum outro verbo expressando existência, tais como existir, surgir, seguidas por um grupo nominal funcionando como Existente.

Segundo Halliday (ibidem), a análise dos processos, de seus participantes e das circunstâncias relacionadas no contexto em que ocorrem as orações permite que percebamos como as categorias semânticas se inter-relacionam, constituindo o sistema de transitividade. 
Podemos notar que na tabela 2 houve uma predominância dos processos primários em relação os secundários, isto significa que as percepções, as emoções, conhecimentos face as interações propostas pelo curso online e a necessidade de participação, formação dos professores-alunos estão sobrepostos as secundários que estão mais relacionados a participação e interação a cursos presencias. 
GRAFICO 1 - Distribuição dos Tipos de Processos em Percentual

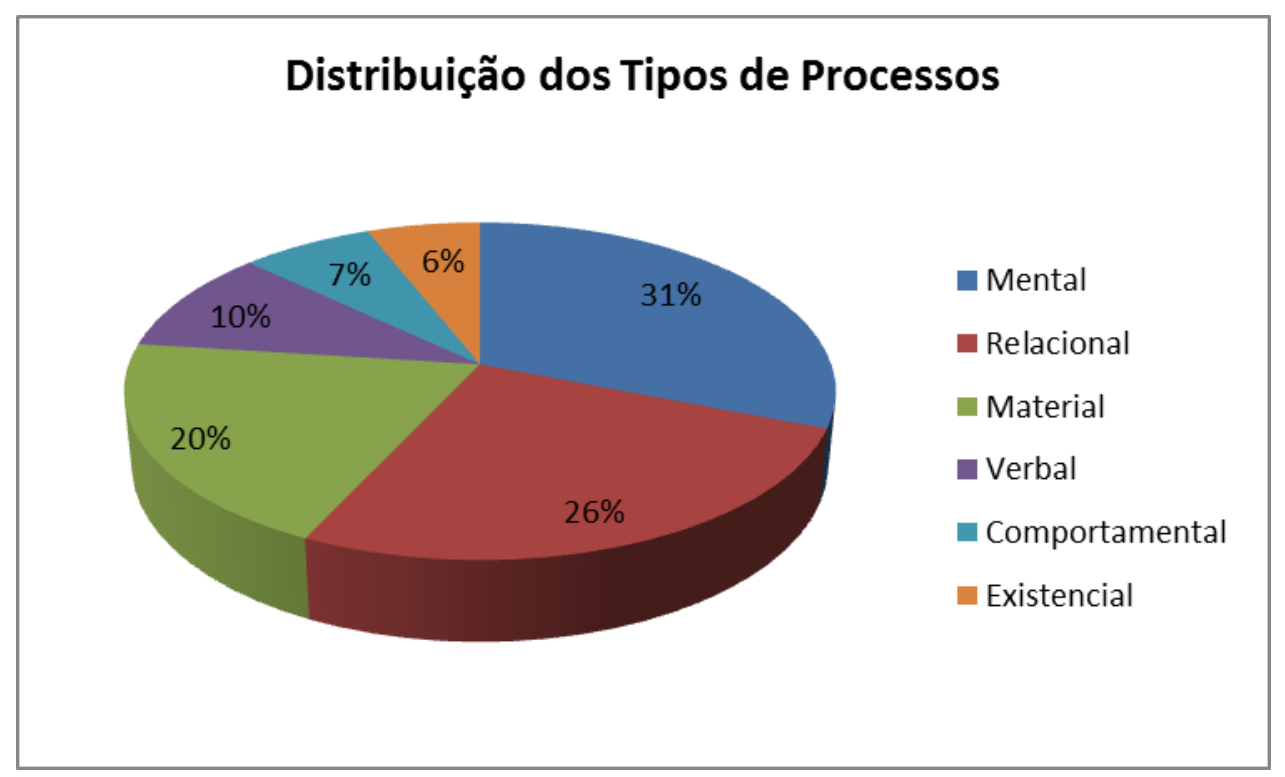

No gráfico 1, podemos notar que dentre os processos primários os mentais foram os mais recorrentes (31\%). O processo mental está presente em orações relacionadas à experiência de mundo da nossa própria consciência, isto é, codifica os significados de pensar e sentir. As orações mentais estão preocupadas com a nossa experiência do mundo de nossa própria consciência. Tais orações são materializadas pelos seguintes processos:

Tabela 3 - Processos Mentais mais Recorrentes

\begin{tabular}{|c|c|c|c|c|c|c|c|}
\hline \multicolumn{2}{|c|}{ PERCEPTIVOS } & \multicolumn{2}{|c|}{ COGNITIVOS } & \multicolumn{2}{|c|}{ DESIDERATIVOS } & \multicolumn{2}{|c|}{ EMOTIVOS } \\
\hline Feel & (26) & Think & (95) & Agree & (42) & Like & (30) \\
\hline Hear & (13) & Learn & (90) & Want & (25) & & \\
\hline See & (03) & Know & (59) & & & & \\
\hline & & Develop & (33) & & & & \\
\hline & & Believe & (39) & & & & \\
\hline & & See $*$ & (27) & & & & \\
\hline & & Study & (26) & & & & \\
\hline & & Reflect & (17) & & & & \\
\hline & & Mean & (10) & & & & \\
\hline
\end{tabular}

- Os processos perceptivos correspondem ao que é sentido pelo experienciador. Exemplos:

\begin{tabular}{|l|l|l|}
\hline They & don't feel & so lonely. (LTS-ICPD) \\
\hline Experienciador & Processo Mental & Fenômeno \\
\hline
\end{tabular}




\begin{tabular}{|l|l|l|}
\hline$I$ & heard & $\begin{array}{l}\text { some comments in the } \\
\text { teachers' room (SRC-WLPD) }\end{array}$ \\
\hline Experienciador & Processo Mental & Fenômeno \\
\hline
\end{tabular}

Nos exemplos, representam os sentimentos e as expectativas dos professores em relação ao curso.

- Os processos cognitivos correspondem ao que é pensado, sabido, imaginado pelo experienciador.

Exemplos:

\begin{tabular}{|l|l|l|}
\hline We & know & $\begin{array}{l}\text { about speeches and texts in } \\
\text { order to understand not only } \\
\text { the words. (GOS-HDWL) }\end{array}$ \\
\hline Experienciador & Processo Mental & Fenômeno \\
\hline
\end{tabular}

\begin{tabular}{|l|l|l|}
\hline$I$ & believe & $\begin{array}{l}\text { education is the root of the } \\
\text { solution. (GBO-WLPD) }\end{array}$ \\
\hline Experienciador & Processo Mental & Fenômeno \\
\hline
\end{tabular}

Aqui os professores-alunos apresentam suas impressões sobre o aprender para ensinar.

- Os processos desiderativos exprimem o desejo, o interesse em algo. Exemplos:

\begin{tabular}{|l|l|l|}
\hline Most of teachers & wants & $\begin{array}{l}\text { Share their information and } \\
\text { experiences. (JCP-ICPD) }\end{array}$ \\
\hline Experienciador & Processo Mental & Fenômeno \\
\hline
\end{tabular}

\begin{tabular}{|l|l|l|}
\hline$I$ & agree & with your points (FB-WLPD) \\
\hline Experienciador & Processo Mental & Fenômeno \\
\hline
\end{tabular}

Nestes excertos os professores-alunos demonstram o desejo de compartilhar suas ideias e aceitar opiniões. 
- Os processos emotivos correspondem às afeições expressas pelo experienciador.

Exemplos:

\begin{tabular}{|l|l|l|}
\hline You & like & Workshops. (DMB-ICPD) \\
\hline Experienciador & Processo Mental & Fenômeno \\
\hline
\end{tabular}

\begin{tabular}{|l|l|l|}
\hline$I$ & like & $\begin{array}{l}\text { to get a time to listen a movie } \\
\text { in English. (LTS-HDWL) }\end{array}$ \\
\hline Experienciador & Processo Mental & Fenômeno \\
\hline
\end{tabular}

Os professor-alunos mostram suas reações em relação às atividades propostas nos fóruns.

Como todos os outros sistemas experienciais, o sistema do tipo de significado constrói a experiência como indeterminada: os quatro tipos diferentes de "sentir" podem misturar-se uns com os outros (FUZER \& CABRAL, 2010: 53). Por exemplo, "see" que é perceptivo (perceber visualmente) pode ser cognitivo (compreender algo).

Exemplos:

\begin{tabular}{|l|l|l|}
\hline$I$ & See (know) & $\begin{array}{l}\text { The importance of the } \\
\text { Professional Development in } \\
\text { the Education area. (ROS- } \\
\text { WLPD) }\end{array}$ \\
\hline Experienciador & Processo Mental & Fenômeno \\
\hline
\end{tabular}

\begin{tabular}{|l|l|l|}
\hline$I$ & See (think) & $\begin{array}{l}\text { training as one of the ways to } \\
\text { be updated. (SRC-WLPD) }\end{array}$ \\
\hline Experienciador & Processo Mental & Fenômeno \\
\hline
\end{tabular}

Outra característica do processo mental é a projeção. Um processo mental pode projetar orações cujo conteúdo é a representação de um pensamento, desejo ou sentimento (HALLIDAY \& MATTHIESSEN, 2004: 206). A projeção, neste caso, é sempre de uma ideia.

Exemplo:

\begin{tabular}{|l|l|l|}
\hline$I$ & like & the idea of asking the \\
\hline
\end{tabular}




\begin{tabular}{|l|l|l|}
\hline & & $\begin{array}{l}\text { students to bring songs or } \\
\text { part of them to class. (VMC- } \\
\text { HDWL) }\end{array}$ \\
\hline Experienciador & Processo Mental & Projeção de uma ideia \\
\hline
\end{tabular}

Como se pode observar na tabela 3, os processos mentais cognitivos tiveram um maior número de ocorrência. Os mais frequentes foram: to think (95), to learn (90) e to know (59) que refletem a visão de ensino-aprendizagem dos professores-alunos que ocorrem pelas interações e trocas de experiências nos fóruns. As orações mentais cognitivas não remetem propriamente aos cinco sentidos, mas trazem o que é sentido, pensado, desejado à consciência da pessoa (FUZER \& CABRAL, 2010).

Os processos mentais cognitivos desempenham duas funções:

a) introduzir o interlocutor na narrativa - trazer uma experiência vivenciada pelo individuo para o momento da enunciação

(i) I think we are in a right way, because technology has come to link people in all the world. (JCP-ICPD)

(ii) I think the listening exercises are the best ones. (FB-HDWL)

(iii) I believe education is the root of the solution to nearly all the problems we face in our modern life. (GOS-WLPD)

b) marcar o conhecimento do experienciadores

(iv) ...we, teachers, need to know and also use the technology in our classes. (JCPICPD)

(v) ...so this course provides me exchanging ideas with other teachers and consequently makes me develop professionally because I've learned so much with them. (TCP-WLPD)

(vi) We share ideas and rethink many aspects related to our job. (EPS-WLPD)

Percebe-se pelos excertos do discurso dos professores-alunos que há um conjunto de concepções do que seria o estudar online: quais posturas são mais adequadas, quais necessidades estruturais devem ser atendidas, quais os modos de interação mais efetivos para cada contexto, entre outros. 


\title{
Considerações finais
}

Este trabalho analisou os processos mentais mais frequentes que introduzem as reflexões dos professores-alunos (experienciador); suas ansiedades, expectativas, insegurança em relação ao novo contexto (curso online), medo em relação a não conseguir atender aos objetivos propostos (fenômeno) e também desespero ao constatar carências sobre seu processo de ensino (sua atuação profissional) e de aprendizagem (enquanto aluno de um curso de formação online).

Os resultados da análise foram obtidos a partir da aplicação do sistema de transitividade que analisou o discurso do professor-aluno a fim de compreender como ele se reconhece como profissional.

Com auxílio da LSF, foi possível verificar algumas de suas representações e conhecer um pouco mais sobre os papéis sociais estabelecidos aos professores de língua inglesa. Alguns verbos podem realizar outros tipos de processos e elencar outras análises dependendo dos participantes envolvidos e do contexto de situação em que estiverem inseridos.

A partir dos dados foi possível também perceber que o processo de aprendizagem em contexto online significa enfrentar a complexidade que ocorre dentro do ambiente virtual e compreender as relações que são estabelecidas. É importante ter clareza do que está explícito e implícito, bem como elaborar estratégias com ferramentas adequadas que minimizam as dificuldades encontradas.

\section{THE CONSTRUCTION OF THE PROFESSIONAL IDENTITY OF THE ENGLISH LANGUAGE TEACHER BY SPEECH IN ONLINE CONTEXT}

\begin{abstract}
The purpose of this paper is to analyze the English-language teacher-student discourse in order to understand and describe how he recognizes himself as a professional. The study is based on the theoretical-methodological perspective of Systemic-Functional Linguistics (HALLIDAY, 1994; HALLIDAY \& MATTHIESSEN, 2004), which seeks to study the social function of the language in use. The analysis sought to apprehend the teacher-student representations that materialize in their linguistic choices. The participants are teacher-students of a training course for teachers of English, Teachers' Links, in online context. The conclusions indicate that the mental process is the most recurrent and is present in prayers related to the world experience of the participants' consciousness, the meanings of thinking and feeling.
\end{abstract}

Key words: Teacher training. English teacher. Systemic-Functional Linguistics. 
Referências

BARBARA, L.; MACÊDO, C. M. M. Linguística sistêmico-funcional para a análise de discurso: um panorama introdutório. Cadernos de Linguagem e Sociedade Brasília: UNB/PPGL, 2009. n. 10, v. 1, p. 89

CELANI, M.A.A. Professores e formadores em mudança: relato de reflexão de um processo de reflexão e transformação da prática docente. Campinas: Mercado das Letras. 2003.

FAIRCLOUGH, N. Discurso e Mudança Social. Trad. I. Magalhães et al. Brasília, DF: Editora Universidade de Brasília, 2001.

FUZER, C.; CABRAL, S. R. S. Introdução à gramática sistêmico-funcional em língua portuguesa. Santa Maria: UFSM, 2010. Mimeo.

GOUVEIA, C. A. M. Texto e gramática: uma introdução à linguística sistêmico-funcional. Matraga 24. Vol. 16 jan./jun. 2009. Rio de Janeiro: UERJ, 2009, p. 13-47.

HALLIDAY, M.K. An Introduction to Functional Grammar. London: Arnould. 1994.

HALLIDAY, M. A. K.; MATTHIESSEN, C. M. I. M. An Introduction to Functional Grammar. 3. ed. London, New York: Arnold, 2004.

MOITA LOPES, L.P. Identidades fragmentadas: a construção de raça, genero e sexualidade na sala de aula. Campinas, SP: Mercado das Letras, 2002.

MOITA LOPES, L.P. Por uma Linguística Aplicada Interdisciplinar. São Paulo: Parábola Editorial, 2006.

NÓVOA, A. Formação de professores e profissão docente. In: Nóvoa, A (coord) Os professores em formação. Lisboa: Dom Quixote, 1992.

RICHARDS, J. C.; RENANDYA, W. A. (Ed.). Methodology in language teaching: an anthology of current practice. Cambridge: Cambridge University Press, 2002.

SCHÖN, D.A. The reflexive practitioner: how professionals think in action. London: Avebury. 1991.

VALENTE, J.A. Análise dos diferentes tipos de software na educação. In: Valente, J.A. (org). O computador na sociedade do conhecimento. UNICAMP/NIED. 1999.

VYGOTSKY, L.S. Pensamento e linguagem. São Paulo: Martins Fontes, 1991. 